\title{
Editorial
}

\section{Innovation, Disruption and Sense-making}

Innovation, specifically innovation in information technology and computing systems, has, in my mind, changed the world more quickly than any other type of innovation we've seen. Whether or not it has improved the world may be subject to debate, but it has definitely sped the rate of change to a pace that is hard to fathom.

One of the most beneficial aspects of information technology is not just the access to information itself but the fact that it gives everyone a voice (provided they have the access in terms of infrastructure and a political climate that allows civil liberties). Certainly there are plenty of examples where social media has promoted discourse on equity and democracy, shared governance, and social justice, and has driven public opinion and even public policy to be more democratic.

Thinking about libraries and their place in providing access to this information, technology innovations have removed the bindings from the traditional books previously housed in our libraries by allowing information to be free from the format and the physical and temporal limitations. Ebooks, or more broadly, electronic information, provide access regardless of the physical location of the reader. Yet, there are still plenty of issues of equity in terms of access to technology or filtering of information by government entities, information conglomerates, corporate and political interests, and foreign powers.

\section{Is it Innovation?}

Everett Rogers, the grandfather (or Godfather?) of innovation theory wrote about innovation and its disruptive influence and diffusion. ${ }^{1}$ However, attributing the changes innovation has brought about to the technology or innovation itself is not entirely accurate. More than technology, society is the driver of change. It is people, individually and collectively, whose decisions and actions incorporate the changes into their daily lives. With such instantaneous call and response now available, social media has become an instrument of change, one that it is impossible to contain or even catch. Looking at recent sociopolitical events in the US-the societal (and political, legal, and educational) change that prompted the \#metoo movement is a prime example. The power of social media is even recognized by the government as is evidenced by presidential tweets that manipulate facts to influence voting and other decisions.

Innovations in information technology have contributed to the open access movement as well. The ideal that information is free is very optimistic but there are issues around the lack of standards and regulation (as we see almost every day in news stories about Facebook, Twitter and even "trusted" news sources). In this day and age, it reminds me of the truism in defense of the second amendment - "guns don't kill people, people kill people." While perhaps a controversial comparison, I think equating information to a tool that has the capability to either promote positive change or damage is representative. Guns are not mediated-they are regulated - and it seems that information and the ways in which people engage with information - as 
consumers, producers, or others - should have minimum standards as well if, for no other reason than to protect personal information, transactions, and safety. The EU made a strong statement with the GDPR ${ }^{2}$ and its consent and transparency of use-while the US with both its gun policies and information policies is really the wild west where almost anything goes.

\section{Is it Disruption?}

With all of the news lately - from protest movements (online and in the real world), political maneuvering, technological advances and missteps, economies up and down and, of course, the changeable weather-one can't help but think about how disruptive it all is. How different events seem to derail momentum (aka "progress"), not just at a personal or organizational level, but at a societal one.

It is not just the events or situations themselves but the multitude of voices that have opinions or provide analyses of them. Mainstream press, social media, governments, scholars, and various communities, citizens and activists all have venues for addressing their concerns and expressing them. It is not noise-but it is often noisy and, at times, downright uncivilwhich only adds to the sense of disruption.

Technology is not the panacea. In some cases, disruptive innovations are explosive and obvious (just look at the prevalence of iPhones or smart speakers) but in other situations, it is stealthy and insidious. Innovation is not limited to technology, it can be ideologies - which may be more difficult to detect in some ways. It cannot exist by itself-it is forever mediated by political, social, economic interests at all levels - at the same time. It seems that it is only in hindsight that we see the good or ill effects of certain innovations but there are certainly issues where the negative implications are more evident-issues around genetic testing, artificial intelligence, and other advances. They tend to generate a lot of response to the potential uses which may lead to mistrust or fear on one side and enthusiasm for pushing boundaries of technology on the other. It is inevitable that these attitudes would clash.

So often the ethics and the standards are lagging behind the technology. Application of the discovery typically comes before any real evaluation or reflection of the discovery (if there's any at all). In an extreme example, criminals will use innovation as a means to an end while law enforcement will struggle to keep up. For every new innovation that is meant to improve our lives, there are criminals who will find a way to exploit it because no one thought ahead about how it could be used divisively. Dishearteningly, technology seems to be driving society - we adopt a certain technology or idea merely because we can. Policy and regulation are far behind and so are the processes of considering the implications, short and long-term.

We think we have appropriated the technology but I wonder if we will find that technology has assimilated us. I will admit that I fall into the portion of the American public that questions the use of AI (in spite of having grown up on Star Trek) - "The public thinks that human-level AI is likely to cause more harm than good, a new report has shown." ${ }^{3}$ Looking back in a few years, we may consider these events or situations, individually or collectively, as a "sea change" or a harbinger of things to come. Progress is generally considered an advance-an evolution that is inevitable and, ultimately, positive. As new technologies continue to emerge, there is the potential of a more equitable or accessible world but, in each case, it seems that we are continuously amidst all of the chaos and disruptions that comes with new ways of interacting. It is only in hindsight that we will know if any of these disruptions lead to "progress," where we can accurately measure the impact and reach, but it is also only in hindsight that we notice their flaws. 


\section{A Call for Librarians to Act as Sense-makers?}

Historically, librarians have been the gatekeepers of information when information was more diffuse and hard to find. Much of our expertise has been in the collecting and organization of information. Enter the Internet-where librarians support open access and the idea that information is free and unmediated with the hope that the apparent ubiquity of the web will encourage individuals to make their own selections.

Librarians have been and continue to be advocates for access to all kinds of information, taking a stance on the neutrality as indicated by the Library Bill of Rights: "Libraries should provide materials and information presenting all points of view on current and historical issues. Materials should not be proscribed or removed because of partisan or doctrinal disapproval." ${ }^{4}$ Neutrality is valued and censorship is decried but it seems like the issue of misinformation and disinformation or the mercenary use of information is not addressed outside of a right to privacy (which, it could be argued, has been traded in favor of personalization).

I have written in the past of the myth of neutrality (which comes from literature on social justice and Marxist theory) but I believe that this is something that librarians can bring to their communities and to society at large. Historically, we brought order to the world of information through call number systems and authority control; we delved into print indexes and followed citation trails. When information broke out of these boundaries, as meta-consumers of information, we engaged in how to be facilitators of access through information. With the shift from sifting through sources for information to having to filter from the deluge, we focused on the technical aspects of access rather than the educational, philosophical, or sociopolitical ones. We favored the idea of disintermediation and removing barriers so individuals could engage directly with the information as though information was also all democratic and not in need of framing.

Going back to Rogers, his categories of adopters is pretty pervasive and librarians often tend to fall toward the early adopters. But I would actually postulate that while librarians may be early to explore technology (and sometimes actually devise it), the descriptor should actually be more critical-looking something like "early skeptic." In this age, librarians have an opportunity - or the need - to come back to a role that is mediating information. But rather than mediating the information itself as a product (which is an option), there is the need to educate and empower individuals to be able to filter information, select relevant and credible sources, and make decisions based on it. While information may (or may not) be free, the importance of being able to find, evaluate, and use it effectively is critical. This is where librarians' expertise, professional ethics, and responsiveness prove invaluable.

It is the shift to focus on information as a commodity and the transfer of it as a transaction that prompts concerns. Librarians have so much more to offer and I think the expertise is overlooked - not just by the faculty and students we serve but by ourselves. While libraries have catered (literally in many cases) to the consumer mindset with cushy furniture and the latest technology, and Starbucks in the library, they have forgotten that the mission of higher education is education - to grow the minds of its students and collaborate with faculty to further discovery and new knowledge. Hand in hand with that mission is that we are custodian of information - not just of the information itself (in terms of preservation) - but of the information as it is transformed into knowledge and what guides it uses. That integrity is not just related to the academics with appropriate attribution and ethical research practice-but 
the appropriate use of the information. Yes, we are not neutral and we are not the information police-but educating information consumers about the implications of the information and how they may use it IS part of our job. It is not for us to advocate a specific point of view-but getting people to ask questions, to think about the implications and their responsible use of information IS.

Librarians have the opportunity - no, the responsibility - to bring order to the chaos, not just to help people filter and find, but to empower them to know how to identify relevant, credible, and balanced information that will help them make decisions or develop new knowledge.

\section{Notes}

1. Everett M. Rogers, Diffusion of Innovations (New York: Free Press, 2003).

2. European Commission, "Data Protection: Rules for the Protection of Personal Data Inside and Outside the EU," available online at https://ec.europa.eu/info/law/law-topic/data-protection_en [accessed 12 April 2019].

3. Karen Hao, "Americans want to regulate AI but don't trust anyone to do it," MIT Technology Review (January 10, 2019) available online at https://www.technologyreview.com/s/612734/americans-want-to-regulate-ai-butdont-trust-anyone-to-do-it/ [accessed 12 April 2019].

4. American Library Association, "Library Bill of Rights," available online at http://www.ala.org/advocacy/ intfreedom/librarybill [accessed 12 April 2019]. 